\title{
PERENCANAAN TATA UDARA SISTEM DUCTING RUANG AULA LANTAI 8 UNIVERSITAS 17 AGUSTUS 1945 JAKARTA \\ Deni Pradana Putra ${ }^{[1]}$, M Fajri Hidayat,ST,MT ${ }^{[2]}$
}

Fakultas Teknik,Program Studi Teknik Mesin,Universitas 17 Agustus 1945 Jakarta

J1. Sunter Permai Raya, Sunter Agung Podomoro Jakarta Utara,14356

Email : Denipradana94@gmail.com

\begin{abstract}
ABSTRAK
Sistem pengkondisian udara merupakan fasilitas yang penting untuk kenyamanan orang yang berada didalam ruangan. Hampir semua kegiatan perkuliahan Universitas 17 Agustus 1945 menggunakan ruang AULA lantai 8 Universitas 17 Agustus 1945, Penelitian ini melakukan perencanaan tata udara sistem ducting ruang aula lantai 8 Universutas 17 Agustus 1945 Jakarta, Menghitung kapasitas beban pendingin dan merencanakan/mendesain tata udara sistem ducting pada ruang Aula lantai 8 Universitas 17 Agustus 1945 Jakarta agar mendapatkan suhu yang sesuai. Prosedur perhitungan beban pendingin menggunakan metode Carrier E-20, dan perhitungan dimensi ducting menggunakan program DuctSizer Keluaran dari McQuay. Hasil akhir penelitian ini diperoleh beban pendingin maksimum pada kondisi puncak sebesar 92203.55 Watt dan hasil perhitungan Desain Ducting yang dipakai : Tinggi : $30 \mathrm{~cm}$ Lebar : $22 \mathrm{~cm}-135.5 \mathrm{~cm}$.
\end{abstract}

Kata kunci : Beban pendingin, Desain Ducting, Tata Udara

\section{ABSTRACT}

Air conditioning systems is an important facility for the convenience of people who were in the room. Almost all the activities of the University lecture 17 August 1945 using the living Hall 8th floor University August 17, 1945, This research do the planning layout of the air ducting system Hall 8th floor Universutas 17 August 1945 Jakarta, Calculating the cooling load and capacity planning/designing the layout of the air ducting system at the living Hall 8th floor 17 August 1945 Jakarta University in order to obtain the appropriate temperature. Cooling load calculation procedure using the method of Carrier E-20, and the calculation of the dimensions of the ducting using program DuctSizer Outputs from McQuay. The end result of this research obtained the maximum cooling load on the peak of 92203.55 Watt and the results of the calculation of the design of the Ducting used: height: $30 \mathrm{~cm}$ width: $22 \mathrm{~cm}-135.5 \mathrm{~cm}$.

Keywords : Load cooling, Ducting, Air Design

\section{PENDAHULUAN}

Sistem pengkondisian udara merupakan fasilitas yang penting untuk kenyamanan orang yang berada didalam ruangan. Ruang aula lantai 8 Universitas 17 Agustus 1945 Jakarta sering di gunakan untuk keperluan kegiatan massal seperti pelepasan wisuda, seminar, temu ilmiah, ujian umum dan acara-acara lainnya. Untuk saat ini ruang aula lantai 8 Universitas 17 Agustus 1945 Jakarta menggunakan air conditioner (AC) Floor Standing.

Air conditioner (AC) Floor Standing sesuai namanya merupakan air conditioner
(AC) yang unit indoornya berdiri/duduk dan bisa dipindah-pindah sesuai dengan keinginan kita. Karena simple dan mudah dibawa kemana-mana, maka banyak orang yang menyewakan model air conditioner (AC) jenis ini. Tapi air conditioner (AC) jenis ini memiliki bnyak kekurangan dengan tinggi nya yang menyamai tinggi manusia angin yang di keluarkan dari air conditioner (AC) ini langsung menyembur ke tubuh yang tidak baik pada kesehatan dan penyebaran dingin yang tidak merata.

Sekarang saya ingin melakukan penelitian bagaimana jika ruang aula lantai 8

Jurnal Kajian Teknik Mesin

Vol. 2 No. 1 April 2017 
Universitas 17 Agustus 1945 sistem tata udara nya dirubah menjadi air conditioner (AC) jenis air conditioner (AC) Central tipe Split Duct. AC Split Duct merupakan air conditioner (AC) yang pendistribusian hawa dinginnya menggunakan Sistem Ducting.

\section{TEORI DASAR}

Tata udara merupakan pengatur udara pada ruangan sehingga mendapatkan temperature udara yang sesuai rcdan nyaman untuk aktivitas dan produktivitas manusia . Ada beberapa jenis pengondisian Udara yang dapat di lakukan.

- Sistem ekspansi langsung.

Pendinginan dilakukan secara langsung, dari evaporator tanpa menggunakan pendistribusian udara.

- Tata udara sistem ducting.

Dimana proses pendinginan udaranya menggunakan pendistribusian udara untuk menyalurkan udara ke seluruh ruangan yg di inginkan.

Teori perhitungan beban pendingin

A. Beban Luar Ruangan (External)

1. Beban Panas Matahari Melalui Kaca.

$$
Q_{g}
$$$$
=A_{1} \times \text { Sun Gain x Shade }
$$

(Watt)

\section{Dimana $=$}

$\mathrm{Q}_{\mathrm{g}} \quad=$ Beban panas matahari melaui kaca(Watt)

$\mathrm{A}_{1} \quad=$ Luas kaca $\left(\mathrm{m}^{2}\right)$

Sun gain =Radiasi matahari $\left(\mathrm{Wat} t \mathrm{~m}^{2}\right)$

Shade factor=Bayangan

2. Beban Panas Matahari Melalui Dinding dan Atap.

$Q_{w r} \quad=\quad A_{2} \quad \mathrm{x} \quad E T D \quad \mathrm{x} \quad U$

(Watt)

Dimana $=$

$\mathrm{Q}_{\mathrm{wr}}=$ Beban panas matahari

melalui dinding dan atap(Watt)

$\mathrm{A}_{2} \quad=$ Luas dinding dan atap $\left(\mathrm{m}^{2}\right)$

ETD $=$ Equivalent temperatur difference $\left({ }^{\circ} \mathrm{C}\right)$

$\mathrm{U} \quad=$ Koefisien perpindahan panas (Watt $/ \mathrm{m}^{2}{ }^{\circ} \mathrm{C}$ )

3. Beban Panas Selain Dinding dan Atap

a. Beban panas melalui kaca pintu masuk, besarnya adalah :
$\mathrm{Q}_{1}=A_{g} \quad \mathrm{x} \quad \Delta t_{g} \quad \mathrm{x} \quad U_{g}$
(Watt).

Dimana $=$

Jurnal Kajian Teknik Mesin

Vol. 2 No. 1 April 2017
$\mathrm{Q}_{1} \quad=$ Beban panas melalui kaca pintu masuk(Watt)

$\mathrm{A}_{\mathrm{g}} \quad=$ Luas pintu $\mathrm{kaca}\left(\mathrm{m}^{2}\right)$

$\Delta \mathrm{t}_{\mathrm{g}} \quad=$ Perubahan suhu pintu $\mathrm{kaca}\left({ }^{\circ} \mathrm{C}\right)$

$\mathrm{U}_{\mathrm{g}} \quad=$ Koefisien perpindahan panas pintu $\mathrm{kaca}\left(\mathrm{Wat} / \mathrm{m}^{2}{ }^{\circ} \mathrm{C}\right)$

b. Beban Panas Melalui Plafon (Ceiling) besarnya adalah :

$\mathrm{Q}_{2}=A_{c} \quad \mathrm{x} \quad \Delta t_{c} \quad \mathrm{x} \quad U_{c}$

(Watt).

Dimana $=$

$\mathrm{Q}_{2} \quad=$ Beban panas melalui plafon (ceiling) (Watt)

$\mathrm{A}_{\mathrm{c}} \quad=$ Luas plafon (ceiling) $\left(\mathrm{m}^{2}\right)$

$\Delta \mathrm{t}_{\mathrm{c}} \quad=$ Perubahan suhu plafon

(ceiling) $\left({ }^{\circ} \mathrm{C}\right)$

$\mathrm{U}_{\mathrm{c}} \quad=$ Koefisien perpindahan panas plafon (ceiling) (Watt $/ \mathrm{m}^{2}{ }^{\circ} \mathrm{C}$ )

c. Beban panas melalui lantai besarnya adalah :

$\mathrm{Q}_{3} \quad=\quad \begin{array}{llllll}A_{f} & \mathrm{x} & \Delta t_{f} & \mathrm{x} & U_{f}\end{array}$

(Watt).....

Dimana $=$

$\mathrm{Q}_{3}=$ Beban panas melalui lantai(Watt)

$\mathrm{A}_{\mathrm{f}} \quad=$ Luas lantai $\left(\mathrm{m}^{2}\right)$

$\Delta \mathrm{t}_{\mathrm{f}} \quad=$ Perubahan suhu lantai $\left({ }^{\circ} \mathrm{C}\right)$

$\mathrm{U}_{\mathrm{f}} \quad=$ Koefisien perpindahan panas lantai $\left(\right.$ Watt $/ \mathrm{m}^{2 \circ} \mathrm{C}$ )

4. Infiltrasi

$\mathrm{Q}_{\text {inf }} \quad=\mathrm{V} \times \Delta t_{\text {inf }} \times P_{\text {udara }} \times \mathrm{C}_{\mathrm{P} \text { Udara }}$

(Watt).....

Dimana $=$

$\mathrm{Q}_{\text {inf }} \quad=$ Infiltrasi (Watt)

$\mathrm{V}=$ Udara infiltrasi $\left(\mathrm{m}^{3} / \mathrm{hr}\right)$

$\Delta \mathrm{t}_{\text {inf }} \quad=$ Perubahan suhu $\left({ }^{\circ} \mathrm{C}\right)$

$P_{\text {udara }} \quad=$ Densitas udara $\operatorname{luar}\left(\mathrm{kg} / \mathrm{m}^{3}\right)$

$\mathrm{C}_{\mathrm{p} \text { Udara }} \quad=$ Kalor spesifik $\left(\mathrm{kj} / \mathrm{kg}{ }^{\circ} \mathrm{C}\right)$

B. Beban Pendingin dalam Ruangan (Internal)

1. Beban Orang Sensibel

$\mathrm{Q}_{\mathrm{ps}} \quad=N \times H G_{s}$ (Watt).

Dimana $=$

$\mathrm{Q}_{\mathrm{ps}} \quad=$ Beban orang sensibel(Watt)

$\mathrm{N} \quad=$ Jumlah orang

$\mathrm{HG}_{\mathrm{s}}=$ Temperatur bola kering sensibel(Watt)

2. Beban Daya Peralatan Listrik

$\mathrm{Q}_{\mathrm{p}} \quad=\frac{\mathrm{P} \times 1}{\eta_{\text {motor }}}($ Watt $)$

Dimana $=$

$\mathrm{Q}_{\mathrm{p}} \quad=$ Beban daya peralatan $\operatorname{listrik(Watt)}$ 


$$
\begin{array}{ll}
\mathrm{P} & =\text { Daya }(\text { Watt }) \\
{ }^{\mathrm{n}} \text { motor } & =\text { fisiensi motor }
\end{array}
$$

3. Beban Lampu Penerangan

$\mathrm{Q}_{\mathrm{L}} \quad=\mathrm{P} \times 1.25 \times 1$ (Watt)

Dimana $=$

$\mathrm{Q}_{\mathrm{L}} \quad=$ Beban lampu penerangan(Watt)

$\mathrm{P} \quad=$ Daya(Watt)

4. Beban ventilasi (Outdoor Air)sensibel

$\mathrm{Q}_{\mathrm{vs}} \quad=O A \times \Delta \mathrm{t} \times \mathrm{BF} \times 1,08$.

Dimana $=$

$\mathrm{Q}_{\mathrm{vs}}=$ Beban ventilasi (outdoor air) sensibel(Watt)

OA $=$ Outdoor Air $\left(\mathrm{m}^{3} / \mathrm{jam}\right)$

$\Delta \mathrm{t} \quad=$ Perubahan suhu $\left({ }^{\circ} \mathrm{C}\right)$

$\mathrm{BF}=$ Bypass Factor

5. Beban Laten Orang :

$\mathrm{Q}_{\mathrm{pl}}=\mathrm{N} \times \mathrm{HG}_{l}(\mathrm{Watt})$

Dimana $=$

$\mathrm{Q}_{\mathrm{pl}} \quad=$ Beban laten orang(Watt)

$\mathrm{N}=$ Jumlah orang

$\mathrm{HG}_{1} \quad=$ Temperatur bola kering laten(Watt)

6. Beban Ventilasi (Outdoor Air) Laten :

$\mathrm{Q}_{\mathrm{vl}}=\mathrm{OA} \times \Delta_{\mathrm{m}} \times \mathrm{BF} \mathrm{x} \quad 0,68$

(Watt)

Dimana $=$

$\mathrm{Q}_{\mathrm{vl}}=$ Beban ventilasi (outdoor air) laten(Watt)

OA $=$ Outdoor Air $\left(\mathrm{m}^{3} / \mathrm{jam}\right)$

$\Delta_{\mathrm{m}} \quad=$ Perbedaan kandungan uap

$\operatorname{air}\left({ }^{\circ} \mathrm{C}\right)$

$\mathrm{BF}=$ Bypass Factor

\section{METODOLOGI PENELITIAN}

3.1 Diagram Alir

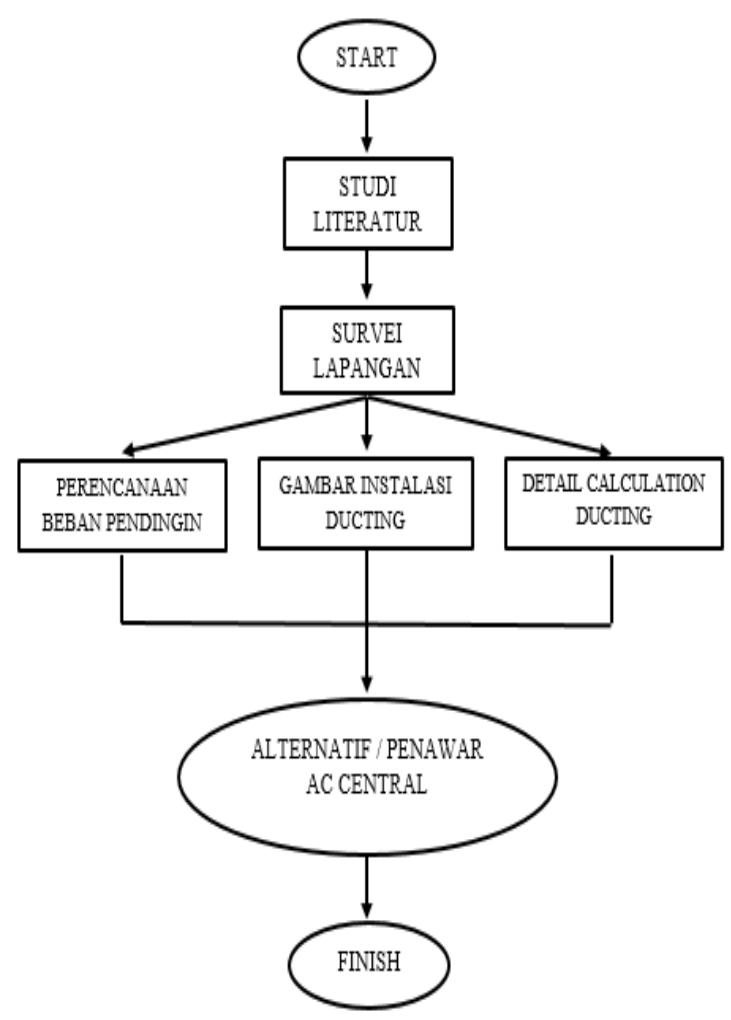

3.2 Identifikasi Masalah

Faktor-faktor yang dapat mempengaruhi beban pendinginan yaitu :

A. Beban Luar Ruangan (External)

1. Beban Panas Matahari Melalui Kaca.

2. Beban Panas Matahari Melalui Dinding dan Atap.

3. Beban Panas Selain Dinding dan Atap

a. Beban panas melalui kaca pintu masuk.

b. Beban Panas Melalui Plafon (Ceiling)

c. Beban panas melalui lantai

d. Infiltrasi

B. Beban Pendingin dalam Ruangan (Internal)

1. Beban Orang Sensibel.

2. Beban Daya Peralatan Listrik

3. Beban Lampu Penerangan

4. Beban ventilasi (Outdoor Air)sensibel

5. Beban Laten Orang

6. Beban Ventilasi (Outdoor Air) Laten

3.3 Perhitungan ducting menggunakan Program Duct Sizer McQuay. 


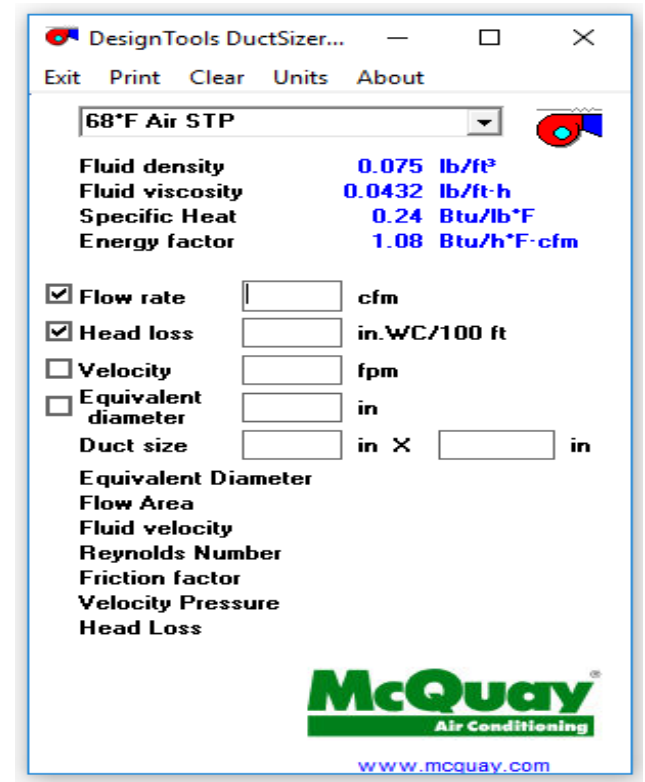

Gambar 3.1 Program Duct Sizer

\section{HASIL DAN PEMBAHASAN}

4.1 Data ruangan.

Tabel 4.1 Data skunder

\begin{tabular}{|l|l|}
\hline \multicolumn{2}{|c|}{ DATA RUANGAN } \\
\hline Luas lantai & $196.5 \mathrm{~m}^{2}$ \\
\hline Luas Plafon & $196.5 \mathrm{~m}^{2}$ \\
\hline Tinggi lantai ke plafon & $7 \mathrm{~m}$ \\
\hline Tinggi lantai ke atap & $8 \mathrm{~m}$ \\
\hline Luas dinding (utara ) & $36.6 \mathrm{~m}^{2}$ \\
\hline Luas dinding (Timur) & $379.1 \mathrm{~m}^{2}$ \\
\hline Luas dinding (Selatan) & $36.6 \mathrm{~m}^{2}$ \\
\hline Luas dinding (Barat) & $375.9 \mathrm{~m}^{2}$ \\
\hline $\begin{array}{l}\text { Luas dinding kaca } \\
\text { ( Timur ) }\end{array}$ & $1.7 \mathrm{~m}^{2}$ \\
\hline $\begin{array}{l}\text { Luas dinding kaca } \\
\text { ( Barat ) }\end{array}$ & $2.71 \mathrm{~m}^{2}$ \\
\hline Penghuni & $360 \mathrm{Orang}^{2}$ \\
\hline \begin{tabular}{l} 
Lampu \\
\hline \begin{tabular}{l} 
TV \\
\hline
\end{tabular}
\end{tabular} & $2 \mathrm{bh}^{2}$ \\
\hline
\end{tabular}

\subsection{Perhitungan beban pendingin.}

Prosedur perhitungan beban pendingin menggunakan metode Carrier E-20. Dari data yang ada dapat dihitung beban panas external dan internal dengan memaikai rumus (1) sampai dengan rumus (8). Hasil Beban pendingin ruang Aula lantai 8 universitas 17 Agustus 1945 Jakarta dapat dilihat Pada tabel 4.2 Jumlah Hasil perhitungan Beban pendingin

Tabel 4.2 Jumlah Hasil Perhitungan Beban Pendingin

\begin{tabular}{|c|c|}
\hline Uraian & Watt \\
\hline Beban Sensibel & \\
\hline Panas melalui kaca & 803 \\
\hline Panas melaului dinding & 17972.31 \\
\hline $\begin{array}{l}\text { Panas melalui pintu } \\
\text { kaca }\end{array}$ & 146.85 \\
\hline Panas melalui Plafon & 1450 \\
\hline Panas melalui Lantai & 3831.75 \\
\hline Infiltrasi & 50 \\
\hline Panas manusia & 28852 \\
\hline Panas peralatan listrik & 1312.5 \\
\hline Panas lampu penerangan & 11610 \\
\hline Ventilasi & 1632 \\
\hline $\begin{array}{l}\text { Total Sensibel Heat } \\
\text { (SH) }\end{array}$ & 67660.41 \\
\hline Safety Factor $10 \%$ & 6766.041 \\
\hline $\begin{array}{c}\text { Room Sensibel Heat } \\
\text { (RSH) }\end{array}$ & 74426.451 \\
\hline Beban Laten & \\
\hline Panas manusia & 12460 \\
\hline Ventilasi & 3701.3 \\
\hline Total Laten Heat (LH) & 16161 \\
\hline Safety Factor $10 \%$ & 1616.1 \\
\hline $\begin{array}{l}\text { Room Laten Heat } \\
\text { (RLH) }\end{array}$ & 17777.1 \\
\hline Room Total Heat (RTH) & 92203.55 \\
\hline
\end{tabular}




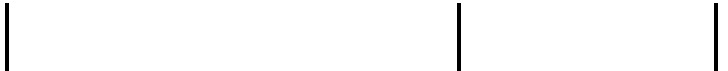

4.3 Pemilihan kapasitas Pendingin

Dari perhitungan pendingin dan aplikasi psikometrik didapat kondisi perencanaan sebagai berikut :

Lantai 8

Kap. $=92203.55$ Watt

Direncanakan setiap lantai menggunakan 2 (dua) buah IU, maka setiap IU untuk lantai 8 akan menerima beban sebesar

Kap. $/ 2=46.101 .77$ Watt

4.4 Pemilihan Mesin Pendingin

a) Pemilihan indoor Unit ( IU )

\begin{tabular}{|c|c|c|c|}
\hline Section & $\begin{array}{c}\text { Flow Rate } \\
\text { (Cfm) }\end{array}$ & Section & $\begin{array}{c}\text { Flow Rate } \\
\text { (Cfm) }\end{array}$ \\
\hline$A-B$ & 4800 & $E-4$ & 480 \\
\hline$B-C$ & 3400 & $F-5$ & 480 \\
\hline$C-D$ & 2880 & B - 6 & 480 \\
\hline $\mathrm{D}-\mathrm{E}$ & 1920 & C - 7 & 480 \\
\hline$E-F$ & 960 & D - 8 & 480 \\
\hline $\mathrm{B}-1$ & 480 & E-9 & 480 \\
\hline $\mathrm{C}-2$ & 480 & $F-10$ & 480 \\
\hline $\mathrm{D}-3$ & 480 & & \\
\hline \multicolumn{2}{|c|}{$\begin{array}{ll}\text { - } & \text { Jumlah Unit } \\
\text { - } & \text { Merk } \\
\text { - } & \text { Model } \\
\text { - } & \text { Kapasitas } \\
\text { - } & \text { Refrigerant }\end{array}$} & $\begin{array}{l}=2 \text { Unit } \\
=\text { DAIKII } \\
=\text { FDR15I } \\
=160.000 \\
=\text { R140A }\end{array}$ & $\begin{array}{l}\text { Y1 } \\
\text { 3tu/h }\end{array}$ \\
\hline
\end{tabular}

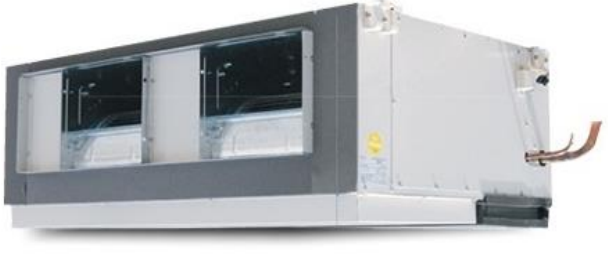

Gambar 4.1 Unit Indoor Air Conditioners

b) Pemilihan Outdoor Unit (OU)

- Jumlah Unit =2 Unit

- Merk = DAIKIN

- Model = FUR15NY1

- Kapasitas $=160.000 \mathrm{Btu} / \mathrm{h}$

- Refrigerant = R140A

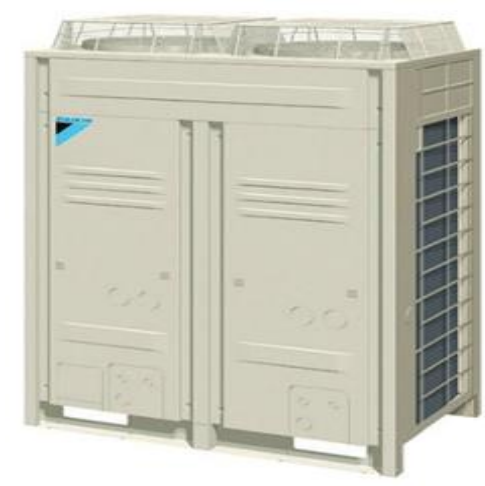

Gambar 4.2 Unit Outdoor Air Conditioners

4.4 Perhitungan ducting menggunakan Duct Sizer

Dalam melakukah perhitungan u kuran ducting menggunakan program Duct Sizer harus menggetaui data-data yang diperlukan, data-data tersebut antara lain :

- Air Flow Rate (cfm)

- Head Loas

Air Flow Rate dapat diketahui pada Tabel 4.3 dan Skematik hasil pembagian Flow Rate dilihat pada gambar 4.. Head Loas untuk Ducting Supply adalah 0.08 in.WC/100ft.

Tabel 4.1 Pembagian Flow Rate setiap section ducting 


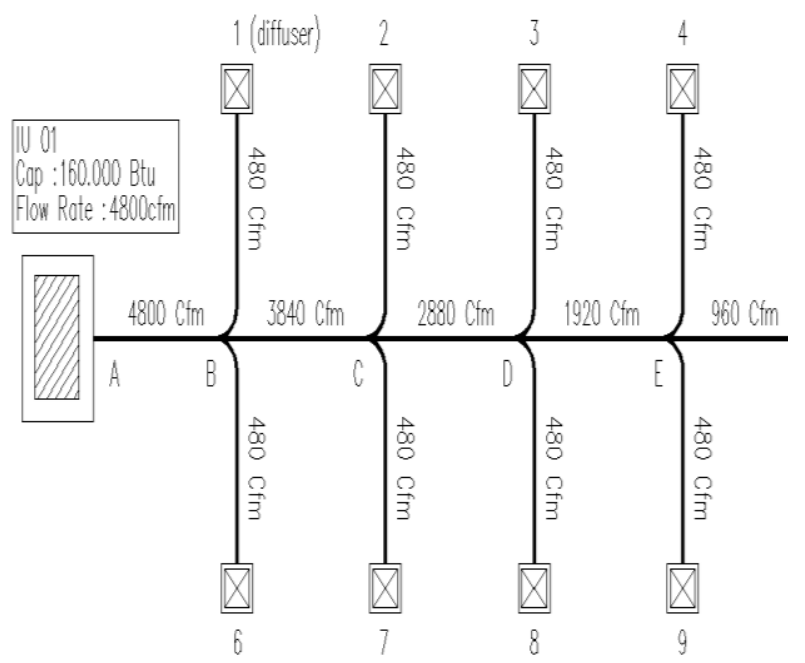

Gambar 4.3 Skematik hasil pembagian

Flow Rate

Tabel 4.22 Tabel hasil peerhitungan dimensi Ducting

\begin{tabular}{|c|c|c|c|c|c|}
\hline \multirow{2}{*}{ Section } & \multirow{2}{*}{$\begin{array}{c}\text { Flow } \\
\end{array}$} & \multicolumn{2}{|c|}{ Rimensi(Eng) } & \multicolumn{2}{c|}{ Dimensi(int) } \\
\cline { 3 - 6 } & Tingi & $\begin{array}{c}\text { Lebar } \\
\text { (in) }\end{array}$ & $\begin{array}{c}\text { Tingg } \\
\text { i (cm) }\end{array}$ & $\begin{array}{c}\text { Lebar } \\
\text { (cm) }\end{array}$ \\
\hline A - B & 4800 & 12 & 55 & 30 & 137.5 \\
\hline B - C & 3400 & 12 & 45 & 30 & 112.5 \\
\hline C-D & 2880 & 12 & 35 & 30 & 87.5 \\
\hline D - E & 1920 & 12 & 35 & 30 & 87.5 \\
\hline E - F & 960 & 12 & 14 & 30 & 35 \\
\hline $\begin{array}{c}\text { B - 1 } \\
\text { (tipikal) }\end{array}$ & 480 & 12 & 9 & 30 & 22.5 \\
\hline
\end{tabular}

\section{KESIMPULAN DAN SARAN}

\subsection{Kesimpulan}

Dari pembahasan yang dilakukan maka dapat ditarik beberapa kesimpulan mengenai hasil analisa PERENCANAAN TATA UDARA SISTEM DUCTING RUANG AULA UNIVERSITAS 17 AGUSTUS 45 JAKARTA adalah sebagai berikut :

a. Jumlah total beban pendingin pada ruang Aula kampus Universitas 17 Agustus 45 Adalah Sebesar 92203.55 Watt.

Jurnal Kajian Teknik Mesin

Vol. 2 No. 1 April 2017 b. Desain Ducting yang dipakai :

Tinggi : $30 \mathrm{~cm}$ Lebar: $22 \mathrm{~cm} \mathrm{-}$ $135.5 \mathrm{~cm}$

\subsection{Saran}

Sebagaimana tujuan diangkatnya judul yang dibahas dalam tugas akhir skripsi ini dari pembahasan dan analisa yang dilakukan, maka kepada para pembaca umumnya dan rekanrekan seprofesi khususnya, penulis menyarankan :

a. Disarankan untuk penggantian dari kondisi sekarang Sistem ac yang ada di AULA lantai 8 kampus Universitas 17 Agustus 45 Jakarta Dengan menggunakan AC Split duck. Karena AC split duck penyebaran udaranya lebih merata di bandingkan AC floor standing yang ada di kondisi sekarang.

b. Disarankan menggunakan Penditribusian Udara ( ducting ) Sebagai media bantu penyaluran udara ke seluruh ruangan.

\section{DAFTAR PUSTAKA}

1) ASHRAE, Air Conditioning, Heating, Ventilation, Refrigertion ( SI Edition)

2) Weather Underground dan Badan Meteorologi Klimatologi dan Geofisika (BMKG).

3) Handbook of Air Conditioning System Design,

4) Carrier E-20 Design,

5) katalog DAIKIN AIR COOLED PACKAGED AIR CONDITIONERS

6) Program Duct Sizer keluaran dari MC QUEY 